\title{
Cost-effectiveness of Universal Hepatitis C Virus Screening of Pregnant Women in the United States
}

\author{
Antoine Chaillon, ${ }^{1}$ Elizabeth B. Rand, ${ }^{2}$ Nancy Reau, ${ }^{3, a}$ and Natasha K. Martin ${ }^{1,4, a}$ \\ ${ }^{1}$ Division of Infectious Diseases and Global Public Health, University of California San Diego; ${ }^{2}$ Perelman School of Medicine, University of Pennsylvania, Philadelphia; ${ }^{3}$ Department of Internal \\ Medicine, Rush University Medical Center, Illinois, Chicago; and ${ }^{4}$ Population Health Sciences, University of Bristol, United Kingdom
}

Background. Hepatitis C virus' (HCV) chronic prevalence among pregnant women in the United States doubled nationally from 2009-2014 ( 0.7\%), yet many cases remain undiagnosed. Screening pregnant women is not recommended by the Society of Maternal-Fetal Medicine or the Centers for Disease Control and Prevention, despite new American Association For the Study of Liver Diseases (AASLD)/Infectious Diseases Society of America (IDSA) guidelines recommending screening for this group. We assessed the cost-effectiveness of HCV screening for pregnant women in the United States.

Methods. An HCV natural history Markov model was used to evaluate the cost-effectiveness of universal HCV screening of pregnant women, followed by treatment after pregnancy, compared to background risk-based screening from a health-care payer perspective. We assumed a HCV chronic prevalence of $0.73 \%$ among pregnant women, based on national data. We assumed no Medicaid reimbursement restrictions by fibrosis stage at baseline, but explored differing restrictions in sensitivity analyses. We assessed costs (in US dollars) and health outcomes (in quality-adjusted life-years [QALYs]) over a lifetime horizon, using new HCV drug costs of $\$ 25000 /$ treatment. We assessed mean incremental cost-effectiveness ratios (ICERs) under a willingness-to-pay threshold of $\$ 50$ 000/QALY gained. We additionally evaluated the potential population impact.

Results. Universal antenatal screening was cost-effective in all treatment eligibility scenarios (mean ICER < $33000 /$ QALY gained). Screening remained cost-effective at a prevalence of $0.07 \%$, which is the lowest estimated prevalence in the United States (in Hawaii). Screening the $~ 5.04$ million pregnant women in 2018 could result in the detection and treatment of 33000 women, based on current fibrosis restrictions.

Conclusions. Universal screening for HCV among pregnant women in the United States is cost-effective and should be recommended nationally.

Keywords. testing; hepatitis C virus; economic; antenatal; pregnancy.

Hepatitis C virus (HCV) infections among pregnant women doubled in the United States from 2009-2014, reaching $8 \%$ in rural Tennessee [1]. Roughly $0.7 \%$ of pregnant women in the United States have a chronic HCV infection [2], equating to $\sim 42$ 000 pregnancies and 29000 births among HCV-infected women annually. Despite the availability of highly-effective ( $>90 \%$ cure) HCV direct-acting antivirals (DAAs) [3], the majority of these women remain undiagnosed and unlinked to care.

Currently, there is disagreement about HCV screening among pregnant women in US clinical guidelines. Recent Society of Maternal-Fetal Medicine and American College of Obstetrics and Gynecology guidelines reaffirmed recommendations for only risk-based testing for HCV among pregnant

Received 16 November 2018; editorial decision 3 January 2019; accepted 18 January 2019; published online January 28, 2019.

${ }^{a}$ N. R. and N. K. M. contributed equally to this manuscript.

Correspondence: N. K. Martin, 9500 Gilman Drive MC0507, La Jolla, CA, 92037 (natasha. martin@bristol.ac.uk).

\section{Clinical Infectious Diseases ${ }^{\circledR} \quad$ 2019;69(11):1888-95}

(C) The Author(s) 2019. Published by Oxford University Press for the Infectious Diseases Society of America. All rights reserved. For permissions, e-mail: journals.permissions@oup.com. DOI: 10.1093/cid/ciz063 women [4]. Similarly, the US Centers for Disease Control and Prevention (CDC) recommends routine screening for human immunodeficiency virus, hepatitis $B$ virus, and syphilis, but not for HCV among pregnant women [5]. By contrast, recent American Association For the Study of Liver Diseases (AASLD)/ Infectious Diseases Society of America (IDSA) guidelines recommend HCV screening for all pregnant women, ideally at the initiation of prenatal care [6]. Additionally, in April 2018, the Kentucky legislature recommended testing pregnant women due to a high HCV burden in that state [7]. For many women, pregnancy is one of their few contact points with health care and health insurance coverage and, as such, pregnancy could provide a critical opportunity for reaching this population. To our knowledge, no study has evaluated the cost-effectiveness of HCV screening in pregnant women in the DAA era in the United States.

To inform HCV screening policies and practices, we assessed the cost-effectiveness of universal HCV screening among pregnant women in the United States, followed by treatment after pregnancy, as determined by state-based Medicaid fibrosis restrictions. 


\section{METHOD}

\section{Overview}

We performed a cost-effectiveness analysis of universal HCV screening among pregnant women in the United States, compared to background, risk-based screening, from a public sector health-care payer perspective. Our cost-effectiveness analysis includes long-term health benefits among pregnant women only, but we additionally examine the potential impact, in terms of HCV diagnoses among children born to HCV-infected mothers, in the Estimation of Impact section.

\section{Baseline and Comparator}

We explored the cost-effectiveness of HCV antenatal screening, followed by treatment after pregnancy, compared to background, risk-based screening. Our main analysis explores the cost-effectiveness in a setting with no treatment restrictions by fibrosis stage, but we additionally explored scenarios with differing treatment eligibilities (see sensitivity analyses).

\section{Model}

We utilized a deterministic, HCV natural history, closed-cohort Markov model of $\mathrm{HCV}$ disease progression and treatment among pregnant women attending antenatal clinics (Supplementary Figure S1). The population was stratified by $\mathrm{HCV}$ infection stage and by HCV diagnosis and follow-up status. We assumed all individuals were diagnosed and under follow-up upon progression to decompensated cirrhosis or hepatocellular carcinoma due to clinical severity. We incorporated losses to follow-up among diagnosed women; individuals lost to follow-up were eligible for retesting in the community. Individuals who attained a sustained virological response (SVR) with Meta-analysis of Histological Data in Viral Hepatitis (METAVIR) F3 or lower were assumed not to progress further for HCV, whereas those with fibrosis stages F4 or beyond progressed at a lower rate compared to their HCV-infected counterparts. Individuals whose treatment failed were not retreated.

\section{Cost-effectiveness Methods}

Cost (in 2018 US dollars [USD]) and health utilities (in quality-adjusted life years [QALYs]) were attached to each health state and discounted by $3 \% /$ year. Due to parameter uncertainty, we performed a probabilistic uncertainty analysis where parameters were randomly sampled from probabilistic distributions (Table 1) to generate 10000 parameter sets. For each parameter set, the model was run and outputs generated. We calculated the mean incremental cost-effectiveness ratios (ICER; \$/QALY gained, mean incremental costs divided by the mean incremental QALYs) for the antenatal screening compared to background risk-based screening for each treatment eligibility scenario, assessing cost-effectiveness under a willingness-to-pay threshold of \$50 000/QALY gained [8].

\section{Sensitivity Analyses on Cost-effectiveness Results}

Due to state differences in Medicaid reimbursement policies by fibrosis stage, we additionally examined scenarios where treatment was restricted until an individual reached METAVIR stage F1 or beyond $(\mathrm{F} 1+)$, METAVIR stage F2 or beyond $(\mathrm{F} 2+)$, or METAVIR stage F3 or beyond (F3+), each compared to background screening. In these restriction scenarios, women with chronic HCV infection would be eligible for treatment upon progression to these disease stages if they remain linked to care.

Additionally, for each treatment eligibility scenario, we performed numerous one-way sensitivity analyses. Due to state variability in $\mathrm{HCV}$ chronic prevalence among pregnant women [1], we examined the impact of varying HCV prevalences. We additionally performed 1-way sensitivity analyses to examine how the ICER changed with alterations in: SVR (85\% and 95\% versus $90 \%$ at baseline), age at pregnancy (22 or 32 compared to 27 at baseline), HCV treatment costs (\$75 000 versus \$25000 at baseline), HCV treatment delivery costs (\$625 USD versus $\$ 1249$ at baseline), proportion previously diagnosed and under follow-up ( $40 \%$ compared to $18 \%$ at baseline), discount rate $(0 \%$ for costs and health utilities or 3\% for utilities and $6 \%$ for costs, versus $3 \%$ for each at baseline), liver transplantation costs $(50 \%$ or $200 \%$ baseline costs), loss to follow-up per year (10/30/50\% per year compared to $12 \%$ at baseline), background testing rate ( $10 \%$ or $0 \%$ per year, compared to $5 \%$ at baseline), baseline fibrosis stage distribution (3\% cirrhosis versus $10 \%$ at baseline), and HCV screening uptake ( $85 \%$ based on hepatitis B virus testing uptake among pregnant women, compared to $100 \%$ at baseline) [9]. Additionally, our baseline fibrosis progression rate among US women produced $15 \%$ cirrhosis or more advanced liver disease at 20 years, but a recent publication among a German cohort found lower rates of progression (21\% cirrhosis or further at 35 years for treatment-naive women [37]), so we evaluated a scenario with lower fibrosis progression rates.

\section{Estimation of US Population Impact}

We additionally estimated the national impact of implementing HCV screening of pregnant women in 2018. Due to state heterogeneity in fibrosis restrictions, we first generated state-level estimates of the number of pregnant women in a given year (number of births + number of fetal losses + number of abortions) [38-40]. We estimated births and abortions by multiplying the number of women aged 15-44 in a given state by the state-specific birth rate and abortion rate, respectively. We estimated fetal losses using the national fetal loss rate, based on CDC recommendations, due to state-level differences in fetal loss reporting by gestational age [38]. As 2016 estimates indicated only $1.6 \%$ of women did not access any prenatal care during pregnancy, for simplicity, we assumed all women would be eligible for screening [41]. Based on state-level estimates of pregnant women in 2018 and state fibrosis restrictions [42], we multiplied the number of pregnant women by HCV identification and 


\begin{tabular}{|c|c|c|c|c|}
\hline State Transitions & HCV Stage & $\begin{array}{l}\text { Mean Sampled Value } \\
(2.5 \%-97.5 \% \text { quantiles })\end{array}$ & Sampling Distribution & Source \\
\hline $\begin{array}{l}\text { HCV chronic prevalence among } \\
\text { pregnant women }\end{array}$ & $\cdots$ & $0.73 \%(0.71-0.75 \%)$ & $\begin{array}{l}\text { Uniform Range: } 0.709- \\
\qquad 0.751\end{array}$ & [2] \\
\hline $\begin{array}{l}\text { HCV antibody prevalence among } \\
\text { pregnant women }\end{array}$ & $\cdots$ & $1.10 \%(1.02-1.20 \%)$ & $\ldots$ & $\begin{array}{l}\text { Calculated based on } \\
\text { spontaneous clearance } \\
\text { rate }\end{array}$ \\
\hline $\begin{array}{l}\text { Proportion who spontaneously clear } \\
\text { their acute infection }\end{array}$ & $\ldots$ & $34 \%(30-38 \%)$ & Uniform Range: 30-38 & [9] \\
\hline $\begin{array}{l}\text { Annual loss to follow-up rates after } \\
\text { HCV diagnosis }\end{array}$ & $\ldots$ & $12 \%(7-17 \%)$ & Uniform Range: 7-17 & {$[10]$} \\
\hline $\begin{array}{l}\text { Proportion of HCV-infected pregnant } \\
\text { women previously diagnosed and } \\
\text { linked to care }\end{array}$ & $\cdots$ & $18 \%(10-25 \%)$ & Uniform Range: 10-26 & {$[11,12]$ See text } \\
\hline $\begin{array}{l}\text { Background testing and linkage rate } \\
\text { per year }\end{array}$ & $\ldots$ & $5 \%(2.6-7.4 \%)$ & Uniform Range: 2.5-7.5 & $\begin{array}{c}\text { Assuming an annual } \\
\text { testing rate of } 10 \% \text { / } \\
\text { year with } 50 \% \text { linked to } \\
\text { care [13] }\end{array}$ \\
\hline $\begin{array}{l}\text { HCV chronic prevalence among } \\
\text { PWID (\%) }\end{array}$ & $\cdots$ & $52 \%(44-59 \%)$ & Uniform Range: 43-60 & {$[14,15]$} \\
\hline \multirow{8}{*}{$\begin{array}{l}\text { Liver disease stage transition rate } \\
\text { per year }\end{array}$} & F0 to F1 & $0.1125(0.996-0.1261)$ & Beta $(251.2107,1984.813)$ & {$[16]$} \\
\hline & $\mathrm{F} 1$ to $\mathrm{F} 2$ & $0.1125(0.996-0.1261)$ & Beta $(251.2107,1984.813)$ & {$[16]$} \\
\hline & $\mathrm{F} 2$ to $\mathrm{F} 3$ & $0.1125(0.996-0.1261)$ & Beta $(251.2107,1984.813)$ & {$[16]$} \\
\hline & F3 to F4 & $0.1125(0.996-0.1261)$ & Beta $(251.2107,1984.813)$ & [16] \\
\hline & $\mathrm{F} 4$ to $\mathrm{DC}$ & $0.0406(0.0312-0.0520)$ & Beta $(58.49116,1380.788)$ & [17-19] \\
\hline & F4 to $\mathrm{HCC}$ & $0.0212(0.0163-0.0276)$ & Beta $(52.83443,2417.472)$ & {$[17-19]$} \\
\hline & $\mathrm{DC}$ to $\mathrm{HCC}$ & $0.0141(0.0016-0.0395)$ & Beta $(1.9326,136.1074)$ & [17] \\
\hline & $\mathrm{DC} / \mathrm{HCC}$ to transplant & $0.0313(0.0014-0.1077)$ & Beta $(1.152814,36.03474)$ & {$[17,19,20]$} \\
\hline Proportion who achieve SVR & $\ldots$ & 0.90 & Uniform Range: 0.85-0.95 & [3] \\
\hline \multirow[t]{5}{*}{ Liver-related death rates per year } & $\mathrm{F} 4$ & $0.0324(0.01716-0.05234)$ & Beta $(12.44677,371.1121)$ & [21] \\
\hline & DC & $0.2210(0.1207-0.3414)$ & Beta $(11.61594,40.93614)$ & [21] \\
\hline & $\mathrm{HCC}$ & $0.2210(0.1207-0.3414)$ & Beta $(11.61594,40.93614)$ & {$[21,22]$} \\
\hline & Transplant year 1 & $0.1715(0.1378-0.2081)$ & Beta $(75.4499,364.4907)$ & [23] \\
\hline & Post-transplant (year $2+$ ) & $0.0353(0.0288-0.0425)$ & Beta $(97.65551,2665.93)$ & {$[23]$} \\
\hline Annual background mortality rate & Varies by age & $\ldots$ & $\cdots$ & $\begin{array}{l}{[2,24] \text { WHO lifetable, }} \\
\text { assuming age } 27 \text { at } \\
\text { pregnancy }\end{array}$ \\
\hline \multirow[t]{3}{*}{$\begin{array}{l}\text { Relative risk of progression if SVR } \\
\text { compared to no SVR }\end{array}$} & F4 to DC & $0.07(0.03-0.2)$ & $\begin{array}{c}\text { Lognormal } \\
(5.6356,2.43983)\end{array}$ & [25] \\
\hline & F4 to $\mathrm{HCC}$ & $0.23(0.16-0.35)$ & $\begin{array}{c}\text { Lognormal } \\
(-3.37754,1.9534)\end{array}$ & {$[25,26]$} \\
\hline & $\mathrm{DC}$ to $\mathrm{HCC}$ & 1 & - & $\ldots$ \\
\hline \multirow{5}{*}{$\begin{array}{l}\mathrm{HCV} \text { fibrosis distribution among } \mathrm{HCV} \\
\text { diagnosed women }\end{array}$} & F0 & 0.16 & $\ldots$ & [27] \\
\hline & $\mathrm{F} 1$ & 0.43 & $\ldots$ & $\ldots$ \\
\hline & $\mathrm{F} 2$ & 0.21 & $\ldots$ & $\ldots$ \\
\hline & F3 & 0.10 & $\ldots$ & $\ldots$ \\
\hline & $\mathrm{F} 4$ & 0.10 & $\ldots$ & $\ldots$ \\
\hline \multicolumn{5}{|l|}{$\begin{array}{l}\text { Cost (all costs inflated to USD } 2018 \\
\text { [28]) }\end{array}$} \\
\hline \multirow{5}{*}{$\begin{array}{l}\text { Annual costs for non-treatment } \\
\text { medical expenses among HCV-in- } \\
\text { fected patients }\end{array}$} & F0-F3 & $\$ 511(\$ 304-734)$ & $\begin{array}{l}\text { Uniform } \pm 50 \% \text { point } \\
\text { estimate }\end{array}$ & {$[29-31]$} \\
\hline & F4 & $\$ 2898$ (\$2009-3786) & $\begin{array}{l}\text { Uniform } \pm 50 \% \text { point } \\
\text { estimate }\end{array}$ & $\cdots$ \\
\hline & DC & \$34 319 (\$32 352-36 330) & $\begin{array}{l}\text { Uniform } \pm 50 \% \text { point } \\
\text { estimate }\end{array}$ & $\cdots$ \\
\hline & $\mathrm{HCC}$ & $\$ 54741$ (\$49 302-60 014) & $\begin{array}{l}\text { Uniform } \pm 50 \% \text { point } \\
\text { estimate }\end{array}$ & $\ldots$ \\
\hline & Liver transplant $Y 1$ & $\$ 225320(\$ 119270-330260)$ & $\begin{array}{c}\text { Uniform } \pm 50 \% \text { point } \\
\text { estimate }\end{array}$ & [30] \\
\hline
\end{tabular}




\begin{tabular}{|c|c|c|c|c|}
\hline State Transitions & HCV Stage & $\begin{array}{l}\text { Mean Sampled Value } \\
(2.5 \%-97.5 \% \text { quantiles })\end{array}$ & Sampling Distribution & Source \\
\hline & $\begin{array}{l}\text { Liver transplant fol- } \\
\text { lowing years }\end{array}$ & $\$ 55196(\$ 28773-81$ 181) & $\begin{array}{l}\text { Uniform } \pm 50 \% \text { point } \\
\text { estimate }\end{array}$ & [30] \\
\hline $\begin{array}{l}\text { HCV antibody test (including con- } \\
\text { sultation) }\end{array}$ & $\ldots$ & $\$ 39$ & $\ldots$ & {$[22,32]$} \\
\hline $\begin{array}{l}\text { HCV RNA test (including consul- } \\
\text { tation) }\end{array}$ & $\ldots$ & $\$ 52$ & $\ldots$ & {$[22,32]$} \\
\hline Liver elastography & $\ldots$ & $\$ 130$ & $\ldots$ & {$[22,32]$} \\
\hline $\begin{array}{l}\mathrm{HCV} \text { antiviral therapy drug cost } \\
\text { only, per treatment course }\end{array}$ & $\ldots$ & $\$ 25000$ & $\ldots$ & $\begin{array}{c}\text { [33] and glecaprevir/ } \\
\text { pibrentasvir wholesale } \\
\text { acquisition cost }\end{array}$ \\
\hline $\begin{array}{l}\text { Treatment delivery costs per } \\
\text { course }\end{array}$ & $\ldots$ & $\$ 1249$ (\$676-1853) & $\begin{array}{l}\text { Uniform } \pm 50 \% \text { point } \\
\text { estimate }\end{array}$ & $\begin{array}{c}\text { [3] Supplementary Table } \\
\text { S1 }\end{array}$ \\
\hline \multicolumn{5}{|l|}{ Health utilities } \\
\hline Uninfected & $\ldots$ & 1 & & [20] \\
\hline \multirow[t]{7}{*}{ HCV-infected patients } & Fo & $0.93(0.83-1)$ & Beta $(59.95413,4.512676)$ & {$[20,34,35]$} \\
\hline & $\mathrm{F} 1, \mathrm{~F} 2$ & $0.86(0.78-0.94)$ & Beta $(29.92649,4.871755)$ & $\ldots$ \\
\hline & F3 & $0.83(0.78-0.89)$ & Beta $(12.30437,2.520171)$ & 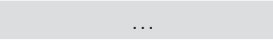 \\
\hline & $\mathrm{F} 4$ & $0.81(0.68-0.89)$ & Beta $(41.6698,9.774397)$ & $\ldots$ \\
\hline & DC & $0.70(0.56-0.79)$ & Beta $(39.8121,17.06233)$ & 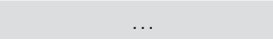 \\
\hline & $\mathrm{HCC}$ & $0.67(0.56-0.78)$ & Beta $(35.508,17.48901)$ & $\ldots$ \\
\hline & Posttransplant & $0.71(0.69-0.79)$ & Beta $(7.612184,3.109202)$ & \\
\hline $\begin{array}{l}\text { Incremental increase in health } \\
\text { utility upon SVR }\end{array}$ & $\ldots$ & 0.05 & & [36] \\
\hline
\end{tabular}

Abbreviations: DC, decompensated cirrhosis; FO-F4, fibrosis stages 0-4; HCC, hepatocellular carcinoma; HCV, hepatitis C virus; PWID, people who inject drugs; SVR, sustained vira response; USD, United States dollars; WHO, World Health Organization.

treatment rates generated from the economic model for each fibrosis restriction scenario, assuming the national HCV prevalence among pregnant women. We summed state-level estimates to generate a national estimate of the total and incremental number of pregnant women identified and treated with $\mathrm{HCV}$ antenatal screening. We also estimated the total and incremental number of HCV-infected children born who would be identified through follow-up screening, based on a maternal diagnosis during pregnancy. For this analysis, we assumed a vertical HCV transmission rate of 5.8\% from a recent meta-analysis [43]. Follow-up testing rates among children born to HCV-infected mothers are uncertain, but a recent study [44] found few (16\%) children born to known HCV-infected mothers were tested at 18 months, as recommended by the AASLD and pediatric societies [6], so we assumed $16 \%$ for this analysis.

\section{Model Parameterization}

All model parameters and sampling distributions are presented in Table 1.

\section{Baseline Population Characteristics}

The baseline population included pregnant women, with an average age of 27 years (based on the median age of reproductive-aged women in the United States) [2]. We assumed a chronic HCV prevalence among pregnant women of $0.73 \%$ (95\% CI 0.71-0.75\%), based on national estimates [2], corresponding to an anti-HCV prevalence of $1.11 \%$, given a $34 \%$ spontaneous clearance rate in women [9]. We assumed a chronic $\mathrm{HCV}$ prevalence among people who inject drugs of $52 \%$ (range $43-60 \%$ ), based on national estimates [14, 15]. Our HCV fibrosis distribution was based on US national estimates for women [27].

Estimates of the proportion of HCV-infected pregnant women diagnosed and currently under follow-up for HCV are unknown. The 2008 National Health and Nutrition Examination Survey (NHANES) survey estimated 50\% of HCV-infected individuals were diagnosed, but this estimated rate was lower among young individuals $(29 \%$ for age <40) [11]. Updated estimates indicate the overall proportion diagnosed has increased by a relative $10 \%$ (from $50 \%$ in 2008 to $55 \%$ in 2017) [12]. Based on this, we assumed $32 \%$ of pregnant women are currently diagnosed, based on estimates among individuals age $<40$ ( $29 \%$ in 2008 , estimated increase by relative $10 \%$ in 2017). We note that one study among HCV-infected pregnant women on opiate substitution therapy (OST) found that $70 \%$ were previously diagnosed, but it is likely this would overestimate the proportion of all HCV-infected women diagnosed and it is unclear how many were under follow-up [45]. The linkage to HCV care rates similarly vary, with recent estimates of $34 \%$ linkage within 6 months among individuals on OST [13] and 55\% among patients receiving care in an outpatient clinic [46]. For this analysis, we estimated that $18 \%$ of infections among pregnant women were diagnosed and linked (32\% diagnosed x 55\% linked). We assumed a $12 \% /$ year loss to follow-up after diagnosis, based on data from pregnant women on OST [10]. 


\begin{tabular}{|c|c|c|c|c|c|}
\hline Scenario & $\begin{array}{c}\text { Cost Per Person, in } \\
2018 \text { USD } \\
\text { Mean (2.5-97.5\% } \\
\text { Intervals) }\end{array}$ & $\begin{array}{c}\text { QALYs Per Person } \\
\text { Mean (2.5-97.5\% } \\
\text { Intervals) }\end{array}$ & $\begin{array}{l}\text { Incremental Cost } \\
\text { Per Person } \\
\text { Mean (2.5-97.5\% } \\
\text { Intervals) }\end{array}$ & $\begin{array}{c}\text { Incremental QALYs } \\
\text { Per Person } \\
\text { Mean (2.5-97.5\% } \\
\text { Intervals) }\end{array}$ & $\begin{array}{l}\text { Mean } \\
\text { ICER } \\
\text { USD/ } \\
\text { QALY } \\
\text { Gained }\end{array}$ \\
\hline Background screening & $\begin{array}{c}921 \\
(443-1397)\end{array}$ & $\begin{array}{c}25.312 \\
(25.297-25.325)\end{array}$ & & $\ldots$ & \\
\hline $\begin{array}{l}\text { Universal antenatal screening and treatment } \\
\text { after pregnancy, regardless of fibrosis stage }\end{array}$ & $\begin{array}{c}975 \\
(442-1510)\end{array}$ & $\begin{array}{c}25.331 \\
(25.315-25.343)\end{array}$ & $\begin{array}{c}53 \\
(-102-175)\end{array}$ & $\begin{array}{c}0.019 \\
(0.010-0.028)\end{array}$ & 2826 \\
\hline
\end{tabular}

Abbreviations: ICER, incremental cost-effectiveness ratio; QALYs, quality-adjusted life-years; USD, United States dollars.

\section{Disease Stage Transition Probabilities and Costs}

Estimates of stage-specific transition rates among women were obtained from published studies [16]. Background (non-hepatitis $C$ related) mortality was time-varying, based on age-specific mortality rates obtained from World Health Organization life tables [24]. Individuals with F0-F3 fibrosis stages who achieved SVR were assumed to have no further disease progression, while individuals with cirrhosis or more advanced disease who achieved SVR could progress at a reduced rate (Table 1$)[25,26]$. We incorporated HCV disease-related costs from published literature [29-31].

Hepatitis C Virus Testing Costs. - We incorporated the costs of antiHCV and HCV RNA confirmatory testing based on the 2018 National Fee Schedule [28]. We assumed individuals are screened first for anti-HCV and, if found positive, are then screened for HCV RNA. Outpatient visit consultation costs were included for each testing visit [47]. For individuals who are RNA positive, we incorporated liver elastography costs for disease staging.

Hepatitis C Virus Treatment Efficacy and Costs.- We assumed a baseline DAA treatment efficacy (ie, rate of SVR) of $90 \%$ for all genotypes [3]. We assumed drug costs for DAAs of $\$ 25000$ per treatment course (based on the wholesale acquisition cost of glecaprevir/pibrentasvir and the price of generic sofosbuvir/ledipasvir and sofosbuvir/velpatasvir available in January 2019) [33]. Cost components of treatment delivery (pre-treatment and on-treatment monitoring) were based upon the IDSA guidelines [3] and the 2018 Clinical Diagnostic Laboratory Fee Schedule [28] (Supplementary Table S1).

\section{Utilities}

Health utilities (in QALYs) were obtained from previously published studies $[17,18,20]$. Consistent with other analyses, we assumed a 0.05 incremental increase in health utility for patients who achieved SVR [48].

\section{RESULTS}

\section{Cost-effectiveness}

Universal HCV screening for pregnant woman was associated with an incremental cost of $\$ 53.2$ (2.5-97.5\% interval -102 to 174) and an incremental increase in QALYs of 0.019 (2.5-97.5\% interval 0.010-0.028) per pregnant woman screened, compared to background, risk-based screening (Table 2). HCV screening for pregnant women with no treatment reimbursement restrictions was cost-effective compared to risk-based screening, with a mean ICER of \$2826 per QALY gained, and fell below the willingness-to-pay threshold of $\$ 50000$ per QALY for $100 \%$ of the simulations.

Screening remained cost-effective for all the alternative treatment eligibility scenarios by fibrosis stage (mean ICERs of \$1934, \$2026, and \$2632 in the METAVIR stage F3+, F2+, and F1+ scenarios, respectively; Supplementary Tables S2-S5).

Screening remained cost-effective for chronic HCV prevalences among pregnant women at or above $0.03-0.04 \%$, varying by treatment eligibility scenario (Figure 1; Supplementary Figure S2). Results were robust to all sensitivity analyses (Supplementary Tables S2-S5). Screening remained cost-effective in all settings with lower fibrosis progression rates $(21 \%$ cirrhosis at 35 years), SVRs (85\%), higher proportions diagnosed and linked at baseline (40\%), lower liver transplantation costs (\$112000 per transplant), higher loss to follow-up rates (50\%/ year), higher background testing rates (20\%/year), and lower proportions of cirrhosis in the baseline cohort (3\%).

\section{US Population Impact}

Given current state-by-state fibrosis restrictions, we estimate screening of the estimated 5.04 million pregnant women in 2018 would result in the detection and treatment of approximately 33000 women overall, and an incremental detection and treatment of approximately 7000 women, with the remainder diagnosed and treated later on in their disease. Screening could additionally result in the detection and treatment of an estimated 300 children born to mothers infected by HCV, and potentially many more if the rate of return for 18-month $\mathrm{HCV}$ testing of children born to $\mathrm{HCV}$-infected mothers increases from the currently observed $16 \%$.

\section{DIsCusSION}

Our analysis indicates that universal HCV screening among pregnant woman in the United States is highly cost-effective and would be associated with the improved detection of HCV among 


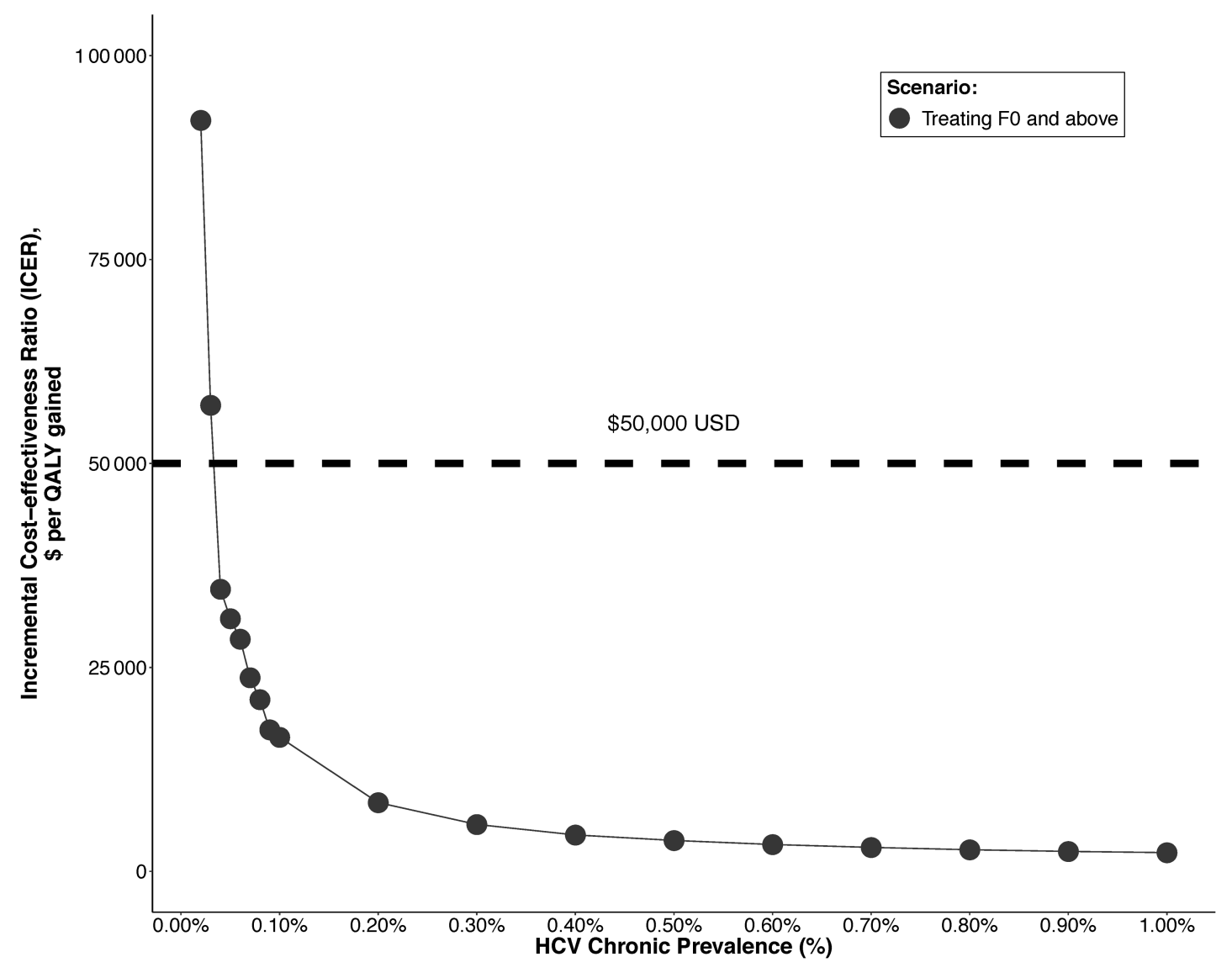

Figure 1. Impact of HCV chronic prevalence among pregnant women ( $\mathrm{x}$-axis) on the ICER (y-axis) of universal screening pregnant woman, compared to background riskbased screening. The willingness to pay a threshold of $\$ 50$ 000/QALY is denoted by a horizontal, dashed line. Abbreviations: F0, fibrosis stage 0; HCV, hepatitis C virus; ICER, incremental cost-effectiveness ratio; QALY, quality-adjusted life-years; USD, US dollars.

women and their children. Our results were robust to variations in state restrictions on reimbursement for HCV treatment. They were additionally robust to variations in HCV prevalences; screening pregnant women is likely cost-effective in settings with chronic HCV prevalence as low as $0.04 \%$. Comprehensive, state-specific data on HCV prevalences among pregnant women are unavailable, but it appears likely all states are above this threshold. Among the states reporting maternal HCV infections on infant birth certificates, HCV rates vary substantially by state, with the highest at 2.2 per 100 births in Tennessee and the lowest at 0.07 per 100 births in Hawaii in 2014 [1]. If these data are representative of the true $\mathrm{HCV}$ prevalence among pregnant women, screening in the lowest prevalence state (Hawaii) would remain cost-effective [1]. As such, our results support calls for a change of the Society of Maternal-Fetal Medicine/American College of Obstetrics and Gynecology and CDC guidelines to recommend the universal HCV screening of pregnant women [49]. Our results also provide additional economic evidence in support of the updated AASLD/IDSA guidelines [6] and the Kentucky legislation [7] recommending screening pregnant women.

To our knowledge, our study is the first to evaluate the cost-effectiveness of HCV screening among pregnant women in the United States. Our findings conflict with a previous study, which found HCV screening among pregnant women in the United States was not cost-effective [50], but that study utilized old, interferon-based treatments with low cure rates. Our findings are consistent with a recent study that found antenatal screening in the UK was cost-effective with newer, interferon-based therapies [51]. Our findings are also consistent with studies that found HCV screening in the DAA era is cost-effective among a variety of US populations, such as for adolescents and young adults in primary-care settings [47], in prisons [52], and in methadone programs [13], and for one-time testing strategies in the general population [53]. We note that our results show that screening is highly cost-effective (ICER $<\$ 3000$ ), more so than previous analyses, primarily because we used new drug costs of $\$ 25000 /$ treatment. When we used treatment costs similar to previous analyses, we found similar cost-effectiveness results as in a recent study examining general-population screening (around \$10 000/ QALY gained) [53].

As with all modeling studies, ours was limited by several factors: most notably, uncertainty in the underlying data. First, there is substantial uncertainty in the proportion of pregnant 
women previously diagnosed and engaged in care, linkage to care rates, and loss-to-follow-up rates among this population in the DAA era. However, despite this, our sensitivity analyses indicated results were robust to uncertainty in these and other parameters.

Second, we did not simulate changing insurance eligibility over time, but note that in some non-Medicaid expansion states, women can lose their insurance coverage as early as 30 days after giving birth. This restriction could limit the timely uptake of HCV treatment. Clinical studies are underway examining the safety and efficacy of HCV treatment during pregnancy. Treatment during pregnancy could reduce the risks of loss to follow-up or loss of insurance coverage after pregnancy, and potentially prevent vertical transmission. Future analyses should explore the health and economic implications of treatment during pregnancy, and should incorporate women's preferences around treatment. For example, in a recent study, only $21 \%$ of $\mathrm{HCV}$-infected women reported a willingness to take DAAs during pregnancy for their individual benefit, but $60 \%$ reported a willingness if it reduces perinatal transmission [54].

Third, our cost-effectiveness evaluation incorporated health benefits among pregnant women only, as the outcome of $\mathrm{HCV}$ diagnoses during pregnancy on subsequent testing among children is uncertain and the pediatric management of $\mathrm{HCV}$ is changing (with studies evaluating treatment among children as young as 2). As such, for the cost-effectiveness analysis, we neglected the additional benefits related to HCV diagnosis and management among babies born to women identified with $\mathrm{HCV}$, although we estimate screening could identify $~ 300$ children born with $\mathrm{HCV}$ as a result of pregnancies in 2018. Even more impact and economic benefits could be accrued due to diagnoses of future children born to these mothers. Unfortunately, the data indicate that the subsequent testing and follow-up rates of their babies are low among HCV-diagnosed women [44]: however, this may improve in the DAA era.

Fourth, we neglected the potential risks of reinfection or population treatment as prevention benefits of treatment. It is uncertain, but possible, that a sizeable fraction of $\mathrm{HCV}$-infected pregnant women remain at risk after pregnancy. However, our previous models show that, in settings with $50 \%$ chronic prevalence among people who inject drugs, like in the United States, the early treatment of people with ongoing drug-injection use is cost-effective and prevents $0.2-0.8$ infections per early treatment, despite the risk of reinfection [55]. As such, including reinfection and prevention benefits would likely increase the cost-effectiveness of screening.

Fifth, our estimates for the population impacts of screening are uncertain, as they are based on state-level estimates of pregnant women and the estimated impact by fibrosis state restrictions, but utilize national estimates of HCV prevalence among pregnant women, due to a lack of state-level data. State fibrosis restrictions are continually changing and will affect the population impact. Additionally, heterogeneity in the $\mathrm{HCV}$ prevalences among pregnant women by state will affect these estimates, and further epidemiological studies are warranted. Nevertheless, we believe our general results indicating the potential, sizeable impact of screening are robust.

In conclusion, our study provides evidence that universal HCV screening of pregnant women in the United States is cost-effective and should be recommended nationally by all clinical societies.

\section{Supplementary Data}

Supplementary materials are available at Clinical Infectious Diseases online. Consisting of data provided by the authors to benefit the reader, the posted materials are not copyedited and are the sole responsibility of the authors, so questions or comments should be addressed to the corresponding author.

\section{Notes}

Disclaimer. Gilead had no influence on the design, analysis, and content of the study.

Financial support. This work was supported by Gilead Sciences.

Potential conflicts of interest. N. K. M. has received funding from the National Institute for Drug Abuse (grant number R01 DA03773) and the University of San Diego Center for AIDS Research (a National Institutes of Health-funded program; grant number P30 AI036214), and unrestricted research grants and honoraria from Gilead and Merck. N. R. has received honoraria from Gilead, AbbVie, and Merck. All other authors report no potential conflicts. All authors have submitted the ICMJE Form for Disclosure of Potential Conflicts of Interest. Conflicts that the editors consider relevant to the content of the manuscript have been disclosed.

\section{References}

1. Patrick SW, Bauer AM, Warren MD, Jones TF, Wester C. Hepatitis C virus infection among women giving birth - Tennessee and United States, 2009-2014. MMWR Morb Mortal Wkly Rep 2017; 66:470-3.

2. Ly KN, Jiles RB, Teshale EH, Foster MA, Pesano RL, Holmberg SD. Hepatitis $\mathrm{C}$ virus infection among reproductive-aged women and children in the United States, 2006 to 2014. Ann Intern Med 2017; 166:775-82.

3. American Association For the Study of Liver Diseases (AASLD)/ Infectious Diseases Society of America (IDSA). Recommendations for testing, managing, and treating hepatitis $\mathrm{C}$

4. Society of Maternal-Fetal Medicine. Hepatitis C in pregnancy: screening, treatment, and management 2018. Available at: https://http://www.smfm.org/ publications/248-smfm-consult-series-43-hepatitis-c-in-pregnancy-screening-treatment-and-management. Accessed November 2018.

5. Centers for Disease Control and Prevention. Pregnancy and HIV, viral hepatitis, STD, \& TB prevention - screening recommendations 2018. Available at: https://http://www.cdc.gov/nchhstp/pregnancy/screening/index.html. Accessed November 2018.

6. American Association for the Study of Liver Diseases. Recommendation for universal hepatitis C screening in pregnancy 2018. Available at: https://http://www. hcvguidelines.org/unique-populations/pregnancy. Accessed November 2018.

7. Kentucky General Assembly (Sponsor Sen. Julie Raque Adams). AN ACT relating to screening for hepatitis C. Signed by Governor (Acts, ch. 125) 2018. Available at: http://www.lrc.ky.gov/record/18RS/SB250.htm

8. Neumann PJ, Sanders GD, Russell LB, Siegel JE, Ganiats TG. Cost-effectiveness in health and medicine. 2nd ed. Oxford (NY): Oxford University Press, 2017.

9. Grebely J, Page K, Sacks-Davis R, et al. The effects of female sex, viral genotype, and IL28B genotype on spontaneous clearance of acute hepatitis $\mathrm{C}$ virus infection. Hepatology 2014; 59:109-20.

10. Krans EE, Zickmund SL, Rustgi VK, Park SY, Dunn SL, Schwarz EB. Screening and evaluation of hepatitis $C$ virus infection in pregnant women on opioid maintenance therapy: a retrospective cohort study. Substance Abuse 2016; 37:88-95.

11. Denniston MM, Klevens RM, McQuillan GM, Jiles RB. Awareness of infection, knowledge of hepatitis C, and medical follow-up among individuals testing 
positive for hepatitis C: National Health and Nutrition Examination Survey 20012008. Hepatology 2012; 55:1652-61.

12. Observatory Polaris Hepatitis C report 2017. Available at: http://polarisobservatory.org/polaris/hepC.htm. Accessed November 2018.

13. Schackman BR, Gutkind S, Morgan JR, et al. Cost-effectiveness of hepatitis C screening and treatment linkage intervention in US methadone maintenance treatment programs. Drug Alcohol Depend 2018; 185:411-20.

14. Denniston MM, Jiles RB, Drobeniuc J, et al. Chronic hepatitis C virus infection in the United States, National Health and Nutrition Examination Survey 2003 to 2010. Ann Intern Med 2014; 160:293-300.

15. Degenhardt L, Peacock A, Colledge S, et al. Global prevalence of injecting drug use and sociodemographic characteristics and prevalence of HIV, HBV, and HCV in people who inject drugs: a multistage systematic review. Lancet Glob Health 2017; 5:e1192-207.

16. Poynard T, Bedossa P, Opolon P. Natural history of liver fibrosis progression in patients with chronic hepatitis C. The OBSVIRC, METAVIR, CLINIVIR, and DOSVIRC groups. Lancet 1997; 349:825-32.

17. Fattovich G, Giustina G, Degos F, et al. Morbidity and mortality in compensated cirrhosis type C: a retrospective follow-up study of 384 patients. Gastroenterology 1997; 112:463-72.

18. Salomon JA, Weinstein MC, Hammitt JK, Goldie SJ. Empirically calibrated model of hepatitis C virus infection in the United States. Am J Epidemiol 2002, 156:761-73.

19. Salomon JA, Weinstein MC, Hammitt JK, Goldie SJ. Cost-effectiveness of treatment for chronic hepatitis $\mathrm{C}$ infection in an evolving patient population. JAMA 2003; 290:228-37.

20. Rein DB, Smith BD, Wittenborn JS, et al. The cost-effectiveness of birth-cohort screening for hepatitis $\mathrm{C}$ antibody in U.S. primary care settings. Ann Intern Med 2012; 156:263-70.

21. Bruno S, Zuin M, Crosignani A, et al. Predicting mortality risk in patients with compensated HCV-induced cirrhosis: a long-term prospective study. Am J Gastroenterol 2009; 104:1147-58.

22. Barocas JA, Tasillo A, Eftekhari Yazdi G, et al. Population-level outcomes and cost-effectiveness of expanding the recommendation for age-based hepatitis $\mathrm{C}$ testing in the United States. Clin Infect Dis 2018; 67:549-56.

23. Montenovo MI, Dick AA, Hansen RN. Donor hepatitis C sero-status does not impact survival in liver transplantation. Ann Transplant 2015; 20:44-50.

24. World Health Organization W. Global health observatory - life tables by country 2018. Available at: http://apps.who.int/gho/data/view.main.60740?lang=en. Accessed November 2018

25. van der Meer AJ, Veldt BJ, Feld JJ, et al. Association between sustained virological response and all-cause mortality among patients with chronic hepatitis $\mathrm{C}$ and advanced hepatic fibrosis. JAMA 2012; 308:2584-93.

26. Morgan RL, Baack B, Smith BD, Yartel A, Pitasi M, Falck-Ytter Y. Eradication of hepatitis $\mathrm{C}$ virus infection and the development of hepatocellular carcinoma: a meta-analysis of observational studies. Ann Intern Med 2013; 158:329-37.

27. Di Martino V, Lebray P, Myers RP, et al. Progression of liver fibrosis in women infected with hepatitis C: long-term benefit of estrogen exposure. Hepatology 2004; 40:1426-33.

28. U.S. Centers for Medicare \& Medicaid Services. Fee schedules. Available at: https://www.cms.gov/Medicare/Medicare-Fee-for-Service Payment/ FeeScheduleGenInfo/index.html. Accessed November 2018.

29. Razavi H, Elkhoury AC, Elbasha E, et al. Chronic hepatitis $\mathrm{C}$ virus (HCV) disease burden and cost in the United States. Hepatology 2013; 57:2164-70.

30. McAdam-Marx C, McGarry LJ, Hane CA, Biskupiak J, Deniz B, Brixner DI. Allcause and incremental per patient per year cost associated with chronic hepatitis $\mathrm{C}$ virus and associated liver complications in the United States: a managed care perspective. J Manag Care Pharm 2011; 17:531-46.

31. El Khoury AC, Klimack WK, Wallace C, Razavi H. Economic burden of hepatitis C-associated diseases in the United States. J Viral Hepat 2012; 19:153-60.

32. U.S. Centers for Medicare \& Medicaid Services. CMS Clinical Laboratory Fee Schedule (CLFS) Available at: https://www.cms.gov/Medicare/Medicare-Feefor-Service-Payment/ClinicalLabFeeSched/Laboratory_Public_Meetings.html Accessed November 2018
33. BusinessWire. Gilead subsidiary to launch authorized generics of Epclusa (sofosbuvir/velpatasvir) and Harvoni (ledipasvir/sofosbuvir) for the treatmen of chronic hepatitis $\mathrm{C}$ - list price of authorized generics to reflect discounts in the system 2018. Available at: https://http://www.businesswire.com/news/ home/20180924005499/en. Accessed November 2018.

34. Thein HH, Krahn M, Kaldor JM, Dore GJ. Estimation of utilities for chronic hepatitis C from SF-36 scores. Am J Gastroenterol 2005; 100:643-51.

35. Chong CA, Gulamhussein A, Heathcote EJ, et al. Health-state utilities and quality of life in hepatitis C patients. Am J Gastroenterol 2003; 98:630-8.

36. Wright M, Grieve R, Roberts J, Main J, Thomas HC; UK Mild Hepatitis C Trial Investigators. Health benefits of antiviral therapy for mild chronic hepatitis $\mathrm{C}$ randomised controlled trial and economic evaluation. Health Technol Assess 2006; 10:1-113, iii.

37. Wiese M, Fischer J, Löbermann M, et al; East German HCV Study Group Evaluation of liver disease progression in the German hepatitis $\mathrm{C}$ virus (1b)-contaminated anti-D cohort at 35 years after infection. Hepatology 2014; 59:49-57.

38. MacDorman M, Kirmeyer S. The challenge of fetal mortality. NCHS Data Brief 2009; $16: 1-8$

39. Jatlaoui TC, Shah J, Mandel MG. Abortion surveillance - United States, 2014 MMWR Surveill Summ. 2017; 66(SS-24): 1-48.

40. Martin JA, Hamilton BE, Osterman MJK; Driscoll AK, Drake P. Births: Final Data for 2016. 2018. National Vital Statistics Reports, 67.

41. Michelle JK, Osterman, Martin JA. Timing and adequacy of prenatal care in the United States. Natl Vital Stat Rep 2016. 67.

42. National Viral Hepatitis Roundtable, Center for Health Law and Policy Innovation of Harvard Law School. Hepatitis C: state of MEDICAID access 2018. Available at: https://stateofhepc.org/. Accessed November 2018.

43. Benova L, Mohamoud YA, Calvert C, Abu-Raddad LJ. Vertical transmission of hepatitis C virus: systematic review and meta-analysis. Clin Infect Dis 2014 59:765-73

44. Kuncio DE, Newbern EC, Johnson CC, Viner KM. Failure to test and identify perinatally infected children born to hepatitis $\mathrm{C}$ virus-infected women. Clin Infect Dis 2016; 62:980-5

45. Krans EE, Zickmund SL, Rustgi VK, Park SY, Dunn SL, Schwarz EB. Screening and evaluation of hepatitis $C$ virus infection in pregnant women on opioid maintenance therapy: a retrospective cohort study. Substance Abuse 2016; 37:88-95.

46. Zuckerman A, Douglas A, Nwosu S, Choi L, Chastain C. Increasing success and evolving barriers in the hepatitis $\mathrm{C}$ cascade of care during the direct acting antiviral era. PLOS One 2018; 13:e199174.

47. Assoumou SA, Tasillo A, Leff JA, et al. Cost-effectiveness of one-time hepatitis $\mathrm{C}$ screening strategies among adolescents and young adults in primary care settings. Clin Infect Dis 2018; 66:376-84.

48. Marfatia S, Gupta K, Mukherjee A, Mattoo V. Direct medical cost associated with the diagnosis and treatment of patients with chronic hepatitis-B in three large metropolitan cities in India - a pilot study. Value Health 2015; 18:A581-2.

49. Jhaveri R, Broder T, Bhattacharya D, Peters MG, Kim AY, Jonas MM. Universal screening of pregnant women for hepatitis C: the time is now. Clin Infect Dis 2018; 67:1493-7.

50. Plunkett BA, Grobman WA. Routine hepatitis C virus screening in pregnancy: a cost-effectiveness analysis. Am J Obstet Gynecol 2005; 192:1153-61.

51. Selvapatt $\mathrm{N}$, Ward $\mathrm{T}$, Bailey $\mathrm{H}$, et al. Is antenatal screening for hepatitis $\mathrm{C}$ virus cost-effective? A decade's experience at a London centre. J Hepatol 2015 63:797-804.

52. He T, Li K, Roberts MS, et al. Prevention of hepatitis C by screening and treatmen in U.S. prisons. Ann Intern Med 2016; 164:84-92.

53. Eckman MH, Ward JW, Sherman KE. Cost effectiveness of universal screening for $\mathrm{HCV}$ infection in the era of direct-acting, pangenotypic treatment regimens. Clin Gastroenterol Hepatol 2018; doi: 10.1016/j.cgh.2018.08.080.

54. Kushner T, Cohen J, Tien PC, Terrault NA. Evaluating women's preferences for hepatitis $\mathrm{C}$ treatment during pregnancy. Hepatol Commun 2018. 2: 1306-10. PMID: 30411077. PMCID: PMC6211328. doi:10.1002/hep4.1264

55. Martin NK, Vickerman P, Dore GJ, et al; STOP-HCV Consortium. Prioritization of HCV treatment in the direct-acting antiviral era: An economic evaluation. J Hepatol 2016; 65:17-25. 